\title{
Professional development combining cognitive apprenticeship and expectancy-value theories improves lab teaching assistants' instructional views and practices
}

\author{
Danny Doucette $\odot$, Russell Clark $\odot$, and Chandralekha Singh $\odot$ \\ Department of Physics and Astronomy, University of Pittsburgh, Pittsburgh, Pennsylvania 15260, USA
}

(Received 24 March 2020; accepted 18 June 2020; published 10 July 2020)

\begin{abstract}
At universities where introductory physics labs are taught by graduate student teaching assistants (TAs), there is a need for specialized professional development for those TAs. This paper presents a specific instantiation of a model for lab TA professional development that uses a combination of cognitive apprenticeship and expectancy-value theories as its framework. We describe how our model was implemented in the lab TA professional development program, which included reflections, role playing, and other pedagogical activities offered through weekly meetings. Our evaluation included an analysis of TA writing and interactions with students alongside informal observations and interviews. We discuss the importance of accounting for TAs' interest and self-efficacy development in teaching the labs, as well as the challenge of motivating TAs who have very low initial levels of interest in supporting student learning. We find that many TAs in our lab TA professional development program demonstrated an improvement in TA performance in supporting student learning. Given that the professional development activities require only a modest investment of time, these positive results suggest that the model of lab TA professional development may be usefully adopted and adapted at other institutions where introductory labs are led by graduate student TAs.
\end{abstract}

DOI: 10.1103/PhysRevPhysEducRes.16.020102

\section{INTRODUCTION}

At large research universities in the U.S., introductory physics labs are often taught by graduate student teaching assistants (TAs). However, prior work has shown that many graduate students may not be ready to effectively lead instruction. In a variety of settings, graduate students adopted less-effective pedagogical strategies for working with students [1-4], demonstrated inadequate understanding of the nature of different problem types [5-7], and demonstrated low levels of pedagogical content knowledge when asked to identify common student difficulties [8-10].

One popular approach is to have graduate students enroll in a course that teaches them about physics pedagogy [11-17]. Prior studies have identified several key elements to effective professional development for graduate student TAs in physics [18]. Focusing on the TA's beliefs and identity as an educator is essential [19-21], as is establishing a purposeful community of practice when working with a group of TAs [22]. Two other important considerations are the importance of respecting and supporting TAs'

*danny.doucette@pitt.edu

Published by the American Physical Society under the terms of the Creative Commons Attribution 4.0 International license. Further distribution of this work must maintain attribution to the author(s) and the published article's title, journal citation, and DOI. emerging competencies as educators $[12,13]$ and the need to clearly align expectations for the work that TAs do with the types of tasks their students perform [23]. Maries [16] identifies three key components to TA preparation: attending to psychological factors such as anxiety about their role as a TA, providing ongoing support, and attending to their beliefs about teaching to achieve buy-in.

The issue of buy-in from the TAs is a critical one if TAs are expected to implement instructional practices with a high degree of fidelity [24-28]. While graduate student TAs may express support for the purpose and goals of a particular curricular strategy, the way they employ that strategy may deviate from what was intended as they navigate the tension between the pedagogy they learn in the professional development program and the desires of their students to minimize the amount of work or "thinking" they are required to do while still achieving good grades $[27,29,30]$. For example, TAs may seek to avoid alienating or frustrating their students, or may seek to make their students' work easier, by providing shortcuts or telling students answers [30]. In particular, while navigating these types of tensions, TAs who choose to use less-effective learning strategies that are not supported by research in physics education may cause their students to learn physics concepts and develop experimental skills less well than they otherwise might [26].

Moreover, while a well-designed and thoughtfully implemented TA professional development course may be helpful, TAs who will lead introductory lab courses 
may require additional, specialized preparation [13,31], such as instruction on pedagogy relevant to the lab, at weekly lab TA meetings [11]. The goal of this paper is to report on a particular instantiation of a lab TA professional development program developed using an iterative approach over several semesters based upon a framework that combines cognitive and motivational theories and describe how it was implemented and evaluated. The evaluation involved the use of informal and structured observations, interviews, and writing prompts for reflection. We discuss the utility of focusing on TA engagement and buy-in and demonstrate that a carefully designed lab TA professional development can have a positive impact on TA attitudes and practice.

\section{THEORETICAL FRAMEWORK AND RESEARCH QUESTIONS}

The theoretical framework for our lab TA professional development is illustrated in Fig. 1 and outlined below. This same framework was also useful in helping TAs reflect upon their students' learning in the lab, which also requires attending to both cognitive and motivational aspects.

The framework guiding our particular instantiation of the model of lab TA professional development integrates cognitive and motivational factors. We took inspiration from the cognitive apprenticeship theory [32] to structure the guidance, scaffolding, and support needed by TAs in order to flourish as educators. Employing the cognitive apprenticeship theory, our model of lab TA professional development focused on first giving TAs opportunities to observe effective pedagogical approaches via demonstration of the criteria for effective performance. Next, we provided coaching and scaffolding as the TAs practiced instructional skills and developed as effective TAs themselves. Finally, the TAs were weaned off the support to help them develop self-reliance. For example, during the lab TA meeting, TAs would observe a demonstration of a TA-student interaction and then be given time to reflect upon, and practice by role playing, that type of interaction with fellow TAs. Individual practice would occur during the TAs' actual lab sections with students. The fact that the TAs were undergoing professional development while also teaching the lab simultaneously was central to the success of our approach.

To account for motivational factors, we grounded our work in expectancy-value theory (EVT) [33,34]. EVT posits that expectancy and value both will influence decision making and determine, e.g., the extent to which the TAs will employ the pedagogical approaches learned in the professional development program in their actual practice as TAs. Expectancy is closely related to Bandura's construct of self-efficacy [35] and can contribute to a graduate student's agency as a TA in implementing effective pedagogical approaches learned in the professional development program. In EVT, value includes the decision maker's interest, attainment value, and extrinsic value in pursing a given course of action, e.g., TAs engaging meaningfully in the professional development program and using pedagogical approaches learned in their actual practice as lab TAs. In particular, EVT describes ways to understand the value individuals discern in the work they do, including attainment value, whereby a TA feels that success is personally meaningful, intrinsic value, whereby the TA experiences some level of individual interest in their work, and utility value, whereby the TA is motivated by the relation of their work to current and future goals [33]. The EVT played an important role in our conceptualization of the lab TA professional development program because we were concerned with the question of whether, and how, lab TAs will choose to engage in our lab

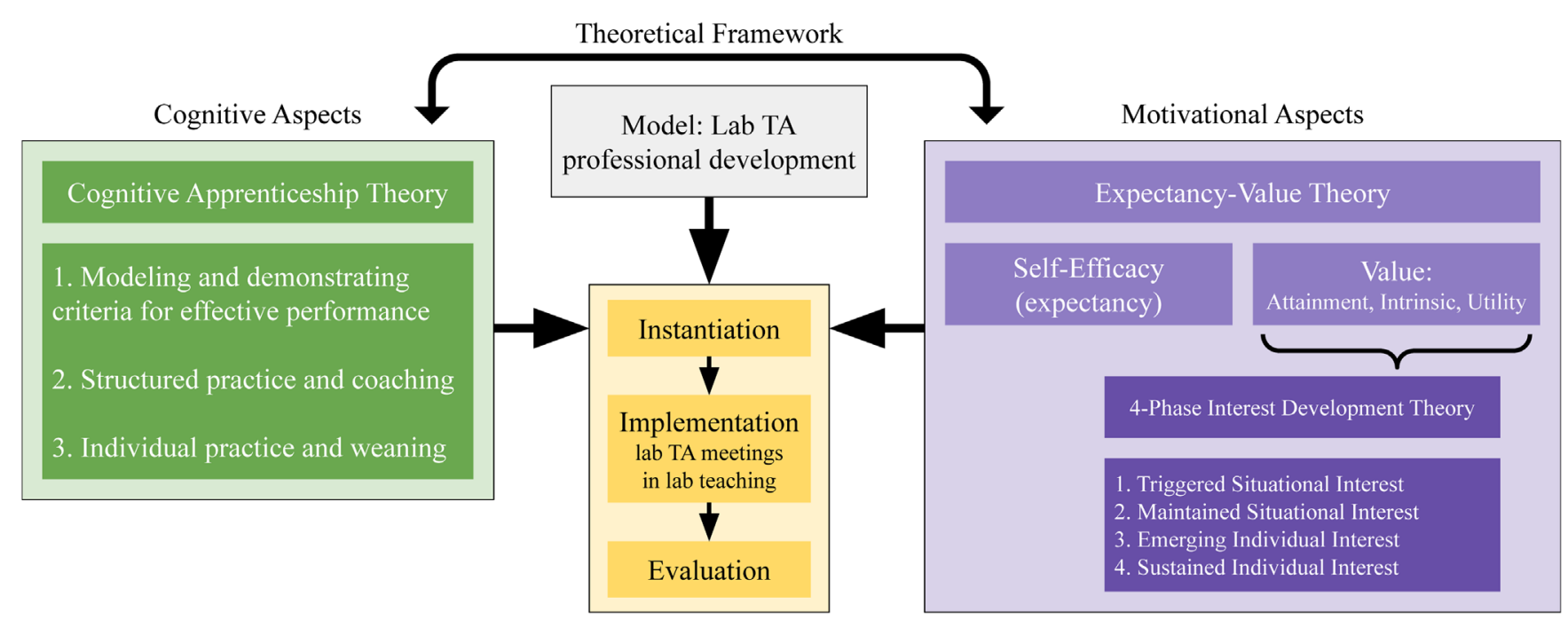

FIG. 1. Framework for this investigation. Cognitive apprenticeship and expectancy-value theories inform the instantiation of our lab TA professional development program. 
TA professional development program, to what extent they change their views about instructional practices, and how they go about interacting with their students in their lab course as a result of the program. In other words, EVT guided us to contemplate the importance of these motivational factors in our professional development program to increase TA engagement and incorporate strategies to increase TA self-efficacy and interest in their use of effective pedagogical approaches learned in their lab sections.

Moreover, we recognized that the TAs in the professional development program will initially be at different levels in terms of their interest in teaching their lab and we must structure the activities and interactions between the TAs in the professional development program as well as the interactions between students and TAs in the lab in such a way that they are productive and propel the TAs to the next level of interest and engagement. We took inspiration from the four-phase framework of interest development [36], which accounts for TAs with different levels of interest, and proposes pathways for TAs to progress to higher levels of interest. In this framework, interactions between the TAs during the professional development activities and between TAs and students during the lab sections may serve, e.g., to provoke situational interest in a TA who would otherwise not place a high value on their TA work. That triggered situational interest might be elevated to the second phase, maintained situational interest, e.g., if the TA is provided with continued support during professional development and feels confident supporting student interactions in their lab sections effectively. The third phase, emerging individual interest, may require that the TAs begin to find personal meaning in their work as TAs. Individual interest development could be supported, e.g., by having the TAs reflect in groups and individually about how they play an important role in shaping their students' learning, gradually giving them more autonomy in coming up with effective strategies for engaging their students meaningfully in the lab and connecting their TA work with their other interests. For example, for a TA interested in equity work, pointing out their role not only in student learning but also in mitigating inequities in the lab has the potential to make them commit to their practice as a TA with greater interest. Finally, for TAs who have extended, personally meaningful practice, the fourth phase of welldeveloped individual interest may be attained. Illustrative examples of how this progression has been enacted by TAs in our professional development program is provided in Table I. At a finer level, we note that TAs may not be described by a single phase of interest development theory for all the aspects of their instructional work. For example, at a given time, a TA may have an emerging individual interest in helping students make connection between their experiments and physics concepts but only situational interest in helping students make accurate measurements.
TABLE I. Example of how a TA's interest might evolve according to four-phase interest development theory when appropriately supported by a professional development program [36].

\begin{tabular}{|c|c|}
\hline Phase & Example scenario \\
\hline $\begin{array}{l}\text { Triggered } \\
\text { situational } \\
\text { interest }\end{array}$ & $\begin{array}{l}\text { The TA sees that a student's experimental } \\
\text { results do not follow the expected trend and } \\
\text { wonders how to talk with the student about } \\
\text { this. }\end{array}$ \\
\hline $\begin{array}{l}\text { Maintained } \\
\text { situational } \\
\text { interest }\end{array}$ & $\begin{array}{l}\text { The TA continues to ponder what the students } \\
\text { might have done to get such unexpected } \\
\text { results. They mention it at a TA meeting } \\
\text { and engage in a discussion ith other TAs } \\
\text { who noticed the same thing in their class. }\end{array}$ \\
\hline $\begin{array}{l}\text { Emerging } \\
\text { individual } \\
\text { interest }\end{array}$ & $\begin{array}{l}\text { The TA begins to think proactively, } \\
\text { predicting where students might make } \\
\text { missteps while they prepare for future labs, } \\
\text { and continues to think about how they can } \\
\text { intervene to help students to check their own } \\
\text { results. }\end{array}$ \\
\hline $\begin{array}{l}\text { Well-developed } \\
\text { individual } \\
\text { interest }\end{array}$ & $\begin{array}{l}\text { The TA takes pride in their work, enjoys } \\
\text { interacting with students, and may begin to } \\
\text { see themself as an educator. They seek out } \\
\text { challenges, such as empathetically spending } \\
\text { additional time with a student who has not } \\
\text { been asking for help but may need extra } \\
\text { support. }\end{array}$ \\
\hline
\end{tabular}

We note that as a prerequisite for TAs engaging productively in the professional development that is offered during the weekly lab TA meetings, it is essential to get buy-in from the TAs. In particular, it is necessary that TAs believe that the professional development activities will help them to become better educators, that their own improvement as educators will help their students learn more effectively, and that both of these things are desirable and achievable. The expectancy-value theory was useful in contemplating this question of how to increase TA buy-in. We probed signatures of growth in TAs' self-efficacy and value as reflections of their buy-in via qualitative analysis, including through informal observations of their lab sections throughout the semester and individual interviews with a subset of TAs.

We evaluated our implementation of lab TA professional development in two ways. First, we investigated whether our lab TA professional development had a positive affect on TAs' views about the learning process. A TA's attitudes toward teaching and learning, and specifically whether they describe their work in terms of a transmissionist or a constructivist lens, can be a powerful predictor of learning [37]. Second, we sought to understand how our lab TA professional development impacted the nature of TA-student interactions while the TAs guided student learning in the lab. Effective evidence-based active engagement learning, for example, that we helped TAs reflect 
upon and practice with other TAs in small groups calls for TAs to dedicate time to supporting student meaning making in open-ended discussion [38-40]. TAs' attitudes toward learning and their behaviors supporting learners were evaluated, e.g., using analysis of writing excerpts and an instructional observation protocol. Our investigation focuses on addressing the following two research questions.

(1) Do TAs' views about teaching and learning change after lab TA professional development?

(2) Do TAs' behaviors as lab instructors change after lab TA professional development?

\section{LAB TA PROFESSIONAL DEVELOPMENT PROGRAM}

Our lab TA professional development model is implemented during weekly lab TA meetings. The first meeting occurs on the Friday before classes start (week 0), and they continue for subsequent Fridays through the semester. The lab TA meetings are run by a senior TA (i.e., a graduate student TA who has taught the lab in a previous semester and shown potential to be successful supporting their peers), with support from the lab coordinator. Although the first author served as the senior TA for the first two iterations of these meetings, we have now implemented the lab TA professional development for three semesters with a senior TA who was not involved in its development. Our aim is that descriptions and video demonstrations of the activities, combined with structural elements of the lab course such as the checkpoints, will serve to "futureproof" our efforts when faculty teaching assignments change and TAs graduate.

The framework described above, including both cognitive and motivational aspects, serves as the theoretical underpinnings to the structure of the lab meeting as a whole, and also for the individual activities that are conducted. We attended to the following principles when designing and implementing our instantiation of the lab TA professional development.

(1) When TAs learn new skills or concepts, they should be guided through the three stages of cognitive apprenticeship.

(2) While TAs enter the professional development program with differing levels of self-efficacy and value related to their work in supporting student learning, all have space to grow as educators.

(3) TAs will evolve in their interest (and consequently, demonstrate increased agency as instructors) according to the four phases outlined above if they are provided adequate opportunities to reflect on their instructional practices, learn and practice new skills, and practice using those skills in their lab sections with their students.

All the lab meetings begin with a group reflection activity in which each TA is asked to share an experience, insight, or concern from the previous week's lab. Sharing
TABLE II. Program of lab TA meeting activities during one semester. Each meeting begins with a reflection activity and a brief apparatus or experiment briefing. Some activities are repeated with the new context of a different lab because it takes time for TAs to develop mastery.

\begin{tabular}{ll}
\hline \hline Week & \multicolumn{1}{c}{ Activities } \\
\hline 0 & $\begin{array}{l}\text { Icebreaker and norms, writing activity } \\
\text { Overview of responsibilities (by lab coordinator) } \\
\text { Socratic dialogue activity } \\
\text { Sabotage activity }\end{array}$ \\
2 & Nature of science discussion, practice \\
3 & Sabotage activity \\
4 & Task division activity \\
5 & Sabotage activity \\
6 & Dominance activity \\
7 & Task division activity \\
8 & Sabotage activity \\
9 & Revisit strategies for supporting inquiry \\
10 & Sabotage activity \\
11 & Revisit nature of science \\
12 & Sabotage activity \\
\hline \hline
\end{tabular}

experiences may help some TAs to transition from a triggered situational interest to a maintained situational interest phase, while their peers can provide support by helping to think about solutions to problems TAs have been facing in their labs. In addition, encouraging all TAs to speak (after being given a prompt and time to come up with something to share) can be especially valuable for English language learners as it helps to normalize oral communication in the lab environment, and in the lab TA meetings specifically.

Following the reflection activity, the lab coordinator shares procedural and apparatus notes about the lab. This takes no more than 10 minutes, and is done in a way that models how the TAs can share relevant information about the procedure and apparatus with their own students. The apparatus is briefly demonstrated, and complex issues and some common student difficulties are identified.

The remainder of the meeting time is devoted to one or more activities, some examples of which are described below. Complete descriptions are available online [41]. The first lab TA meeting includes an icebreaker activity that asks TAs to briefly discuss what worries and excites them about working in the lab, as a way to promote growth in their self-efficacy (by seeing that others are worried too) and the way they value their work (by normalizing excitement about leading lab sections). An example program of activities for one semester is outlined in Table II. The activities and program were developed, iterated, and trialed prior to their implementation, so that the evaluation below follows a relatively mature implementation of our lab TA professional development program. 


\section{A. Sabotage activity}

In the "sabotage" activity, two TAs engage in a role play that helps them to better understand the apparatus and experiment while also practicing TA-student interactions in a realistic and relevant scenario. A lab station is set up with data collection and/or analysis completed in line with a certain stage of the lab procedure. However, one piece of the apparatus, procedure, or analysis has been done incorrectly, or sabotaged. For example, a sensor may be uncalibrated, a dynamics track may not be level, a circuit may be constructed with a short, incorrect units may be used, data on a graph may be displayed in a confusing way, or a linear trend line might be applied to nonlinear data.

One of the participants will role play as a student, and may need a quick briefing about this stage of the lab procedure. This is usually provided in the form of a couple of sentences on a slip of paper (e.g., "You have collected these data indicating the position and time of a falling object, and drew a linear fit on the position-time graph using the computer. However, the line doesn't seem to fit the data perfectly, and you're not sure what the slope represents."). The other participant role plays as a TA. The "TA" approaches the "student" and initiates a conversation. The TA aims to help the student resolve the issue with the experiment, but must do this using techniques that support inquiry learning (e.g., standing on the side, not touching the apparatus, only asking questions). Following the role play, the participants reflect on their experiences; e.g., the students discuss what they found helpful and the TAs discuss the strategies they employed to help the students.

The TAs who attend the weekly meetings appreciate this activity because it gives them practice dealing with common student difficulties, which are often the inspiration for the sabotage. The TAs also get the opportunity to practice interacting with students in a low-stakes setting, and they receive feedback from their peers, the senior TA who organizes the lab meetings, and the lab coordinator. In addition, the TAs get a chance to experience how students feel when they receive support from a TA.

\section{B. Task division activity}

Prior research has identified task division (e.g., based on gender) as a possible cause for inequitable work in introductory physics labs [42-44]. In this activity, TAs are shown what this type of inequitable task division looks like and there is discussion of strategies for countering it in their labs.

In pairs, the participants are asked to engage in a challenging lab exercise, such as constructing a certain circuit. After most of the pairs are finished, the senior TA shares their observations of pairs in which one participant was more engaged than their partner, and then explains that adopting gendered modes of work (e.g., women taking on secretarial roles while men do the tinkering), among others, is a common "bad habit" [45] and that one strategy to countering task division is to regroup students once or twice per semester.

Next, the participants are randomly assigned new partners and asked to complete another, similar task, such as building a different type of circuit. This time, they should be mindful of their own roles, and also watch other groups around the room. Once the participants finish this second task, they reflect as a group on what they saw and experienced. The senior TA shares some relevant strategies for countering inequitable task division (assigned roles, negotiating fair task splits, giving students individual opportunities to develop core skills). This type of reflection is designed to help TAs understand what inequitable task division looks like, and why it is problematic, before giving them tools to respond when they see it in their own labs.

\section{Dominance activity}

Another way that inequities can manifest in group work is through domination of discussions. Based on work by Turpen and co-workers [46,47], this activity gives TAs an opportunity to observe conversation dominance, and to discuss and practice discursive techniques they can use to address imbalanced interpersonal dynamics. First, two participants (recruited in advance) act as quiet and dominant students. A third participant is chosen to act as the TA. The rest of the group observes while the TA role plays a check-in with the two actors.

After the role play, the two actors share their experience and the observers are invited to both comment on what they saw and suggest "teaching moves" that the TA could make in such a situation to bring forward the voice of the quieter student. This rich, participant-driven discussion typically touches on topics such as body positioning, nonverbal cues, and tone and speaking patterns, as well as on the question of who is being recognized, praised, or ignored in TA-student interactions. TAs also discuss which student is being recognized and being given an opportunity to develop their self-efficacy as a physics person. Finally, the participants break into groups of three to replicate the scene they just observed. Each participant is given a chance to try some teaching moves as the TA, to get practice implementing them, develop their interest, and to see what works best for their own style of interacting with students.

\section{Nature of science discussion}

One aspect of the "thinking skills" identified by our faculty is the need for students to understand the broadscope epistemology of experimental science, sometimes called the nature of science [48]. For this activity, TAs engage in discussion to unpack the meaning of "the basic beliefs and attitudes that scientists share about what they do and how they do their work" [49], then reflect individually and as a group on how they might be able to have discussions with their students about these beliefs. 
The goal here is to have TAs generate both understandings and approaches themselves, which could stimulate their emerging individual interest (or help them progress along the axis of four-phase interest development theory) while also providing meaningful, practical strategies for talking about the nature of science with their students. As reported elsewhere [50], this approach to introducing discussions about the nature of science to the lab course was generally unsuccessful, and will be a focus for future work (see below).

\section{METHODOLOGY}

\section{A. Participants}

This study reports on implementation of the lab TA professional development at our large state-related research university in the U.S. with a student population of 18000 undergraduate students and 12000 graduate students. Our data reflect a total of 44 sections of the introductory physics lab, led by 30 different TAs, during 2018 and 2019.

Each lab section meets for 3 hours, once per week, for a semester. In the lab, 24 students work in pairs at a lab bench that is equipped with a computer. In addition, and before their weekly lab section, students also attend a onehour lecture delivered by the lab coordinator that aims to (re)introduce the key physics concepts the students will be exploring during the lab. The lab is a one-semester class that is taken separately from lecture-based Physics 1 and 2 courses, and focuses on physics concepts from Physics 1 and 2, including mechanics, electricity and magnetism, and optics, and requires completion of Physics 1 as a prerequisite.

The lab sections were led by graduate student TAs who had completed, or were currently enrolled in, a onesemester course on physics pedagogy. $80 \%$ of the TAs were international students, $70 \%$ identified as male, and $85 \%$ were in their first or second year of graduate school. Nearly all of the data reported below are for TAs who were teaching the one-semester lab course for the first time. The high fraction of lab TAs who were international students may be the result of a policy requiring better results on an English proficiency test in order for a TA to be appointed to lead recitations. Interestingly, in our interviews with students, they rarely indicated they had difficulty understanding their TA.

Two offerings of the introductory physics lab are offered: an algebra-based version that accounts for the majority of lab sections and attracts primarily health science majors, and a calculus-based version that primarily enrolls physical sciences majors. Aside from some small differences in the presentation of the theory in the lab lecture, the lab is identical for these two offerings. For our student population, those who wish to apply to medical school (and several similar career trajectories) require a physics lab, while most engineering students are not required to take a physics lab. The algebra-based offering is about $60 \%$ female, and primarily students in their third or fourth year of study. The calculus-based offering is $30 \%$ female, and primarily students in their first or second year of study.

\section{B. Traditional and transformed lab curricula}

Our observations and data follow TAs who instructed two types of introductory labs. For the first two semesters, the labs followed a traditional, highly structured format [51]. In the traditional lab course, students read a section of their lab manual that developed the theory, then carried out experiments in a step-by-step manner that was designed to allow them to operate sometimes-complex apparatus efficiently, but left little room for students to develop experimental skills or develop their epistemological understandings of experimental science.

For the third semester of our study, the labs were transformed to an inquiry-based format. The process of transforming physics labs has been thoughtfully described in prior research [52,53], and our work followed a similar process. We started by meeting with faculty in our department to identify goals for the introductory physics lab courses. Using the AAPT recommendations as a guide [54], the emergent consensus was a focus on improving fundamental lab skills such as making measurements, creating graphs, troubleshooting, and enhancing thinking skills such as understanding models, devising hypotheses, and developing scientific arguments [55].

In addition, our faculty members decided that the introductory physics lab should also aim to help students improve their understanding of essential physics concepts by having students engage with inquiry-based lab work. For some time, physics educators have argued that the introductory physics lab should focus on inquiry, rather than highly structured laboratory work [56,57]. Inquirybased lab work such as RealTime Physics [58], which we adopted as the foundation for our lab curriculum, provides scaffolding as students develop their conceptual understanding of physics concepts in the lab. We have supplemented the RealTime Physics labs with additional learning activities and questions to explicitly help students develop the lab and thinking skills our faculty members identified as priorities.

In an effort to improve the quality and quantity of TA-student discussions and feedback about physics concepts and lab-related thinking skills, we introduced a series of checkpoints to work that students do in the lab [59]. In particular, 2-4 times during the three-hour lab session, students are expected to summon the TA for a brief chat about their work. TAs are provided with a list of possible questions to ask at each checkpoint and a checklist to ensure every pair of students completes all the checkpoints.

The adoption of RealTime Physics as a lab curriculum required the TAs to not only help students develop skills to 
troubleshoot apparatus and computer problems [60], but also support inquiry-style learning. However, since our professional development program aims to prepare lab TAs to support principles of guided inquiry and inclusion in student learning, this new curriculum was even more attuned to the TA training provided.

\section{Collecting qualitative evidence for TA buy-in and growth}

As a precondition to being able to evaluate the change in TA behaviors that come as a result of our implementation of lab TA professional development, we sought to determine whether the TAs bought into the professional development we provided. We relied on two approaches to do this: informal observations and semistructured interviews. An extensive series of informal observations were conducted by all three authors, who acted as nonparticipant observers, during the semesters for which data were collected $[61,62]$. These observations occurred during the weekly lab TA meetings, during lab sessions, and occasionally even at times when TAs were preparing for the lab individually. Field notes were recorded and used as a basis for generative discussion by the authors to identify key themes (which then provided focus for future observations) and to evaluate the extent and nature of TA buy-in to the professional development program. These informal observations complemented the structured observations we conducted (see below) and, along with the interviews, were used in part to examine TA buy-in to our instantiation of the lab TA professional development model. In total, more than 200 hours of informal observations were conducted. See Fig. 2 for a diagrammatic representation of our data collection.

We invited eight TAs to participate in semistructured interviews about their experiences as a lab TA. The eight TAs were selected to provide diversity in standing (graduate students in their first and second years of study, as well as those close to graduation), nationality, gender, teaching experience, and our perception of their engagement with the lab TA meetings. The interviews occurred at the end of the semester in which they served as a lab TA, were audio recorded and transcribed, and lasted 30-45 minutes. All eight invited TAs participated. The interviews followed a semistructured format [61]. A list of "starter questions," generated by the authors, focused on the TAs' perceptions of the structure and goals of the lab TA professional development program, their experiences working with students, how, and to what extent, they used techniques from the lab TA meetings in their labs (such as supporting inquiry learning, maintaining equitable learning, and explicitly talking about the nature of science), and the grading for the lab course. Most participants shared openly and at length about most topics, with little need for prompting. All names are pseudonyms chosen by the interview participants.

\section{Writing excerpts}

In order to understand how TAs' views about learning changed over the semester that they taught, we asked the lab TAs to respond to writing prompts at their first and last lab meetings. The prompts, reproduced in Table III, were designed to stimulate TAs to write about how they imagined or recalled interacting with students. The written TA responses were read by the authors, and all statements describing interactions with students were extracted. The extracts were typically one sentence in length, but in a small number of cases where a single sentence contained multiple potentially conflicting viewpoints, that sentence was split into two or three phrases.

Next, we sorted the extracts according to whether they indicated that the TA held a transmissionist or constructivist understanding of the nature of learning, using the following

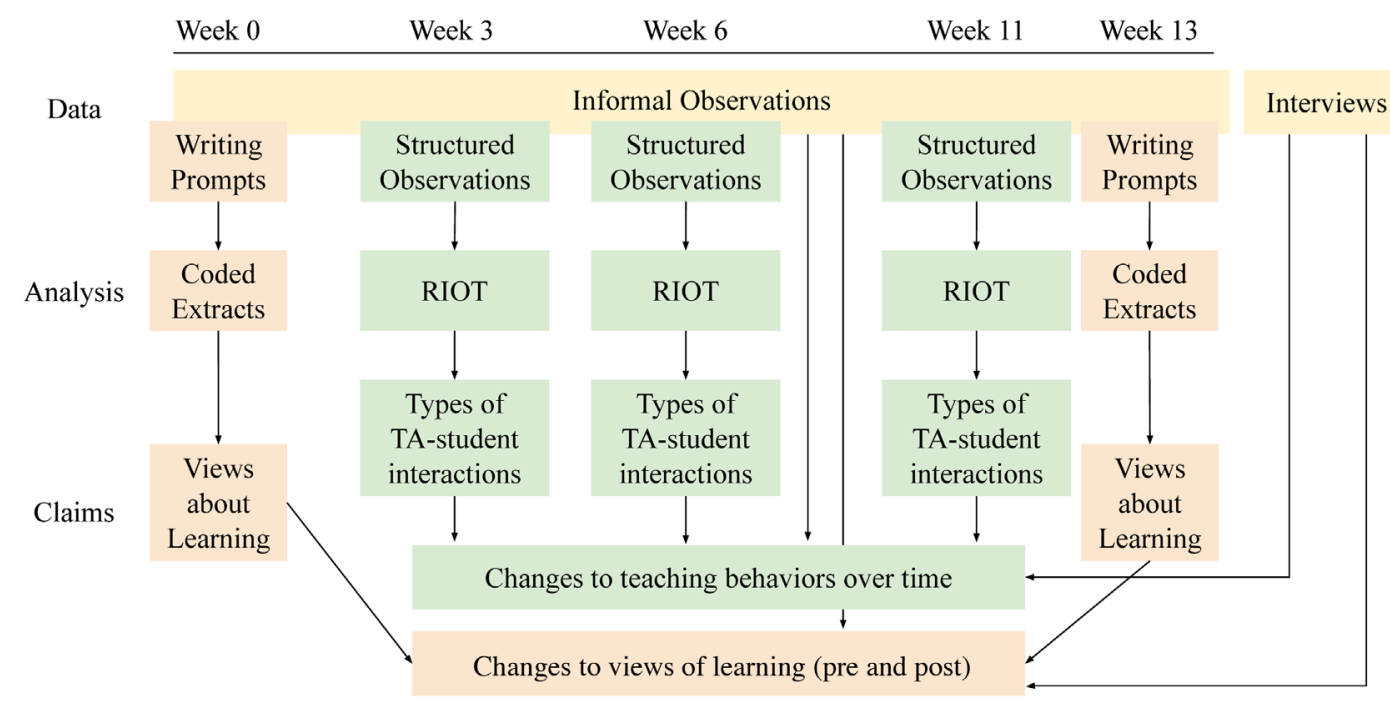

FIG. 2. Diagrammatic representation of data collection over the course of a typical semester. 
TABLE III. Writing prompts used to generate writing excerpts.

\begin{tabular}{cl}
\hline \hline Pre & What can we do as TAs to make sure our students have \\
positive, meaningful, effective learning experiences? \\
Pre & $\begin{array}{l}\text { How will you help students understand how physics } \\
\text { concepts connect to the lab, and understand why they're } \\
\text { doing what they're doing? }\end{array}$ \\
Post & $\begin{array}{l}\text { Write about a time when you helped a student learn } \\
\text { something in the lab. }\end{array}$ \\
Post $\quad \begin{array}{l}\text { Write about an occasion in the lab when you weren't } \\
\text { sure what to do at the time. How would you react now? }\end{array}$ \\
\hline \hline
\end{tabular}

definitions, selected from a journal article written for an audience of college educators. In the transmissionist view, the instructor "has the knowledge and transmits that knowledge to the students, who simply memorize the information often without even thinking about it. This model of the teaching-learning process assumes that the student's brain is like an empty container into which the [instructor] pours knowledge" [63]. Meanwhile, for the constructivist view, "... knowledge is a state of understanding and can only exist in the mind of the individual knower; as such, knowledge must be constructed, or reconstructed, by each individual knower through the process of trying to make sense of new information in terms of what that individual already knows Students use their own existing knowledge and prior experience to help them understand the new material. The [instructors] role is to facilitate students' interaction with the material and with each other in their knowledge-producing endeavor" [63].

Over three semesters, we collected 61 written excerpts from 24 different TAs, all but two of whom were TAs in a lab for the first time. Two physics education researchers first sorted ten of the excerpts, then compared their results and discussed their sorting process in order to reach a consensus before sorting the remainder of the excerpts. Overall, the sorters achieved an agreement given by Cohen's $\kappa=0.929$ [64], which is considered "excellent" [65] or "almost-perfect" [66] agreement. Finally, a consensus was reached for the remaining excerpts for which there was disagreement. All 61 excerpts were sorted into one of the two categories.

Trusting this sorting to answer the research question requires the validity of several assertions. First, we claim that the excerpts honestly and accurately depict the TAs' thoughts about student-TA interactions. The TAs who submitted these responses were given time and space to write, assured that their work would be held anonymous, and understood that their supervisor (the lab coordinator) would not evaluate the responses. These conditions, plus the existence of several responses from the end of the semester of professional development meetings that directly oppose explicit instructions from the TA training, suggest that the TAs' responses were honest and true.
TABLE IV. Example excerpts.

\begin{tabular}{|c|c|}
\hline Category & Example excerpts \\
\hline Transmissionist & $\begin{array}{l}\text { "I will explain the physics model behind their } \\
\text { experiment equipment." } \\
\text { "I need to map the theoretical background } \\
\text { deeply and communicate it in such a way that } \\
\text { the students are able to grab the concepts." }\end{array}$ \\
\hline Constructivist & $\begin{array}{l}\text { "... encourage students to design an } \\
\text { experiment by themselves to prove the } \\
\text { formula." } \\
\text { "I was able to refrain from giving students an } \\
\text { answer until they had figured it out } \\
\text { themselves Through questions, I was able to } \\
\text { get them to the answer." }\end{array}$ \\
\hline
\end{tabular}

Second, we claim that the sorters were correctly reading and interpreting the excerpts. Although there were a few grammatical and spelling errors in the (handwritten) excerpts, they were all clear and coherent. Examples are provided in Table IV. Further, given the high level of agreement between the two sorters, it is highly likely that they were reading and interpreting the excerpts accurately. We note that since the first constructivist statement in Table IV was from a TA in the traditional lab which focused on "proving formulas," the researchers agreed that it was constructivist for that context.

The final claim that must be supported in order for this sorting to have validity is that the categories into which the excerpts are sorted must be distinct, and that a TA moving from one category to another is making a meaningful change in their view of student learning. In this case, the two categories of transmissionist and constructivist views are relatively distinct, with a wealth of educational theory supporting this claim $[32,67]$.

\section{E. RIOT observations}

The Real-time Instructor Observation Tool (RIOT) is a tool for continuously monitoring and categorizing types of instructor-student interactions [68,69]. The categories are briefly described in Table $\mathrm{V}$ and more thoroughly explained in Refs. [68,70]. While a wide variety of observation protocols have been developed and used to study instructor-student interactions in labs [71,72], the continuous recording, ease of use, and applicability of categories made RIOT the best option for this study.

Our RIOT data span three semesters, totaling nearly 200 hours of observations of 24 different TAs. The data were collected in weeks 3, 6, and 11 of the semester. These weeks were chosen to provide initial, midpoint, and end-ofsemester data because student enrollment is still in flux during weeks 1-2 and students often skip the experiment during week 12 since they are permitted to drop their lowest lab report grade. 
TABLE V. Descriptions of categories in RIOT relevant to this study. For full descriptions, see Refs. [68,70].

\begin{tabular}{|c|c|}
\hline Category & Description \\
\hline Open dialogue & $\begin{array}{l}\text { Student is contributing half of the } \\
\text { words, actively developing an } \\
\text { understanding of physics/lab ideas }\end{array}$ \\
\hline Closed dialogue & $\begin{array}{l}\text { Instructor is controlling the } \\
\text { conversation, but student is providing } \\
\text { some input (asking follow-up } \\
\text { questions, answering closed } \\
\text { questions, etc.) }\end{array}$ \\
\hline $\begin{array}{l}\text { Explaining content } \\
\text { (discussing concepts) }\end{array}$ & $\begin{array}{l}\text { Instructor is explaining physics } \\
\text { concepts while student is a passive } \\
\text { recipient }\end{array}$ \\
\hline Clarifying instructions & $\begin{array}{l}\text { Instructor is explaining lab procedure } \\
\text { while student is a passive recipient }\end{array}$ \\
\hline (Actively) listening & $\begin{array}{l}\text { Instructor is actively listening to a } \\
\text { student, shown by eye contact, body } \\
\text { position, gestures, etc. }\end{array}$ \\
\hline $\begin{array}{l}\text { Active observing or } \\
\text { watching (one group) }\end{array}$ & $\begin{array}{l}\text { Instructor is paying attention to only } \\
\text { one group of students but is not } \\
\text { engaging with them in any way }\end{array}$ \\
\hline $\begin{array}{l}\text { Passive observing or } \\
\text { scanning (whole class) }\end{array}$ & $\begin{array}{l}\text { Instructor is walking around or on } \\
\text { side, not able to pick out individual } \\
\text { conversations }\end{array}$ \\
\hline
\end{tabular}

During data collection, the observer sat on a bench at the side of the classroom, using the RIOT app [70] to collect data on his mobile phone. The observer was careful to avoid impacting the regular classroom dynamics. In followup interviews with TAs, the TAs confirmed that they did not act differently when the observer was in the room because they were there so frequently.

The validity of RIOT data for answering our research question requires several assertions to be true. First, we claim that the observer could see, hear, interpret, and correctly understand conversations that were happening around the classroom. For example, when the TA is talking with a pair of students on the far side of the room, was the observer able to accurately categorize their interaction based on what he could hear and see? In order to assess this, we video recorded sample interactions from two different distances and with different audio levels, representing the experience of observing a pair of students working together from across the bench and from across the lab. As part of a regular lunch meeting of the DisciplineBased Science Education Research Center (dB-SERC) at our university, we asked a panel of 27 experienced science educators to categorize the interactions. At both distances, all 27 educators were able to accurately and correctly distinguish between the open dialogue and closed dialogue categories of student interaction. These two categories were used because we felt that they were likely the most difficult to distinguish at a distance. The videos we used are available online in Ref. [41].

Second, we claim that the observer was accurately and precisely categorizing the TA-student interactions that they observed. To evaluate this, a second observer was given descriptions of the categories, and then simultaneously categorized interactions during four separate one-hour intervals. Data from one of these intervals is shown in Fig. 3. Agreement between the two observers for the four intervals ranged from Cohen's $\kappa=0.50$ to 0.73 , which corresponds to a "fair to good" [65] or "moderate" to "substantial" [66] level of agreement. This should be viewed as a lower-bound estimate on the agreement between the observers. In particular, if one observer were pressing the buttons slightly earlier than the other, this systematic temporal shift between two otherwisein-agreement categorizations would bias the agreement downward [73]. A difference in prior experience in using the RIOT tool and diligence in focusing on interactions may explain some of the other discrepancies between the two observers. We acknowledge that this range of values for Cohen's $\kappa$ is lower than is reported in other physics education literature, but note that real-time categorization as we do here is more susceptible to error than sortingtype categorization (as we did with the writing excerpts), for which the researchers have time to carefully reflect before making a categorization decision. Thus, we claim that our categorizations are consistent, and likely accurate, but with relatively sizable random errors. We exercise due caution and restraint in analyzing the data and drawing conclusions that result from this approach.
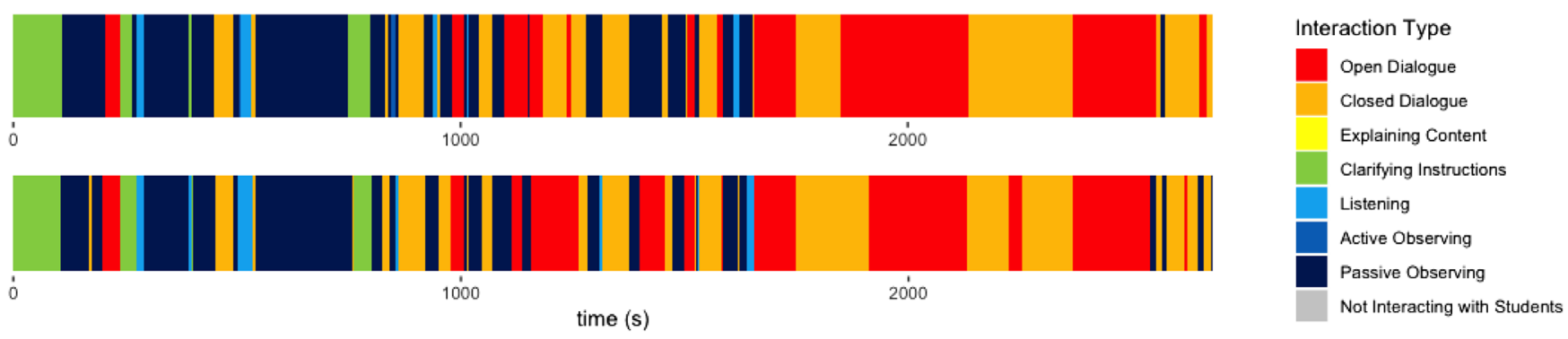

FIG. 3. Comparison of two observers' categorizations during a representative 45-minute interval. Definitions of the categories are found in Table V. Not all interaction types were observed during this session. 
Finally, in order to draw conclusions from RIOT data, it is necessary that the categories are real and meaningful in the context in which they were observed. For example, were TAs acting in a substantially different way when they were engaging in open-ended dialogue as opposed to closed dialogue? In order to evaluate this claim, we asked our panel of science educators to categorize a variety of video-recorded sample interactions. If the experienced instructors can identify and explain the difference between different interaction types, then those interaction types are likely to be pedagogically meaningful. A panel of 24 educators at $\mathrm{dB}$-SERC were asked to categorize video reenactments of five different TA-student interactions. In all five cases, there was a strong level of agreement among the educators. Fleiss's kappa [65] for these 24 raters categorizing five videos using the RIOT categories was calculated to be $\kappa=0.82$, which is an "almost-perfect" [66] level of agreement.

\section{RESULTS}

In order to understand TAs' views about the lab TA professional development program and the extent to which we had established buy-in from them, we conducted interviews with eight TAs about their experiences as TAs and as participants in the professional development program. Below are summaries from three of those TAs. The first two, from interviews with Alan and Emily, are representative and typical of the TAs we interviewed and also of the broader pool of 24 TAs who completed the TA professional development program. Alan and Emily crystalized some factors that were common across many of the other interviews. The third summary is from Ted, a TA with a uniquely low level of buy-in, whose responses help to identify a shortcoming in our professional development program. Ted's responses indicate that for a TA who started with very low interest and self-efficacy, the professional development program was not able to help him develop a higher level of interest and self-efficacy as a facilitator of the inquiry-based labs. Our observations suggest that Ted's experiences were unique among the 24 TAs included in this investigation. All names are pseudonyms.

\section{A. Alan}

A first-year graduate student, Alan reported that his semester as a TA in the introductory lab was his first teaching experience. In the interview, he described how his confidence as a physicist and an educator grew substantially because of his work as a TA: "I was not confident in so many of the materials I had learned before, and I realized that I have to take another look at some of them .... How am I going to teach these things some day?"

Alan enjoyed teaching, and his description of a typical interaction with students suggests a well-developed individual interest on the four-phase framework: "Some people think that the voltage is flowing through the circuit. I saw their answers in their homework, I didn't know they think like this in the lab... You could talk about some things and their confusion. It was very rewarding for me, that I could help them in a small way."

Alan was a typical participant in the lab TA meetings. When asked what he found effective in the professional development, he answered, "There was nothing not effective, all of it was really helpful.... [We] did those sabotage things, [and] introduced some of the common mistakes. I don't know what would happen if we didn't have those sessions." Yet, while he was actively engaged in the meetings, he was sometimes unsuccessful at implementing the teaching strategies in his lab sections. In a discussion about standing on the side of the lab bench and asking questions, rather than touching the apparatus, when students have questions, he confessed, "I have to admit that I wasn't able to do it correctly because sometimes it's really hard to stay away from the thing that they're asking questions about, I have to go there and see what's happening." Here, it appears that Alan's self-efficacy as an educator is developing, but has not fully matured, reminding us that supporting the growth of educators can be a slow process.

For other strategies, such as switching partners to help students avoid developing "bad habits" like gendered task division $[42,45]$, Alan implemented the strategy introduced in the TA professional development, but clearly kept thinking about it, as he explains, "When I ask a question in the check-in, most of the time one of them answers.... If I were to do everything again, I would change their partners every session, not once a semester. I really notice that some of them keep staying away from the experiment, and their partner is doing all of the things. It's one of the most important things that we have to work on." Whether this technique would be effective is perhaps less important than what it says about Alan's well-developed individual interest and engagement as a TA.

\section{B. Emily}

Emily was in her fourth year as a graduate student, doing research in experimental condensed matter physics. This was her first semester as a TA. Like Alan, she rapidly developed an individual interest as a lab TA. Although initially planning to pursue a career in industry after graduating, by the end of the semester she was considering a teaching role instead: "I went from, a year ago, absolutely, post-doc or private researcher. And now, I'm thinking of ... teaching full time. This [lab] has done a lot to show me that I can interact with students and have a lot of fun."

Emily was enthusiastic about the lab TA meetings. Asked whether they helped her prepare for her work as a lab TA, she replied, "Definitely yes, the meetings helped, [especially] the parts of the meetings where we go see what the set-up is like, and go practice it." Emily found the sabotage activity to be especially useful. She also 
appreciated having the opportunity to reflect and connect with fellow lab TAs, reflecting growth in her self-efficacy while noting that "it's nice knowing that we can all check in with each other, just knowing that the time is there." Emily reported that the nature of science activity was less effective, and suggested that discussions about the nature of science might be better positioned as questions for the lab report rather than part of the discussions between TAs and students.

Unlike Alan, Emily told us that the strategies to support inquiry learning "came really easily." She relished the guide-on-the-side role, and preferred to help students find their own answers by asking them questions. "I loved the check-in after Investigation 2, capacitors in series and in parallel, trying to get them to understand why they add up the way they do. Some students had the answer, and some didn't. It was really fun helping them arrive at that, because it was so intuitive and physical. I enjoyed that part the most, when they let me ask them a bunch of questions." Like Alan, Emily's responses suggest a lab TA with welldeveloped individual interest and positive self-efficacy growth as an educator in her work by the end of the lab professional development program.

\section{Ted}

Ted was the lab TA who was least willing to engage with the activities during our lab TA meetings. A fifth-year graduate student, Ted studies theoretical condensed matter physics. Unlike Alan and Emily, who demonstrated buy-in to the principles of supporting inquiry and inclusive learning, among others, Ted remained skeptical about the value of learning pedagogical techniques in the lab TA meetings. Asked if he found the meetings valuable, he replied, "A bit. I think the best way to hold the lab meeting is to give us a complete instruction about the lab. For example, we could do the experiment together." Ted saw the lab meetings as a place to learn about the lab procedure and apparatus, rather than an opportunity to learn new teaching strategies and get practice interacting with students.

While Ted saw the pedagogy, he did not adopt it. Asked if he sought to help students to frame their own questions, he answered, "There were too many students. I can't just instruct them step by step. There's not enough time." Similarly, he decided not to adopt the strategy of talking to quieter students in order to counteract conversational dominance, saying, "Trying to ask the student who is not good at physics, I think they cannot answer your question."

However, while Ted did not buy into the teaching approaches we shared during the professional development program, he did recognize the problems those approaches were designed to address. He described a case of gendered task division, saying, "One student is very good at physics, they will try to do most of the work." However, while he was concerned about this happening, he felt unprepared to address it. When asked how he responded when such situations arose in his lab, Ted said, "I have no very good ideas. I told them to mix their groups several times, but it didn't help."

This situation of a TA who sees the need for certain teaching strategies, but does not use them when they are presented to him, suggests that Ted did not consider that the teaching strategies he was being presented had merit. In other words, he did not buy into these strategies. Moveover, and exceptionally, during his 30-minute interview Ted told no stories about interactions with particular students, expressed no curiosity or interest in a student's struggle or success, and indicated no pride or interest in his teaching. Ted's lack of buy-in could be understood by hypothesizing that Ted never felt a triggered situational interest in helping students learn during his work as a lab TA.

Aside from Ted, however, we may broadly claim that our instantiation of the model of lab TA professional development had a positive impact on TAs. Not only did most of the TAs (except for Ted) participate actively in the lab TA meetings, but they continued to reflect on their role as a TA outside of the meetings and worked to improve the way that they supported student learning in their lab sections. Thus, since most of the TAs have demonstrated that they bought into our instantiation of lab TA professional development, we may consider the evaluation of our implementation of that instantiation.

\section{Did TA views about teaching and learning change to be more supportive of inquiry learning?}

Over three semesters, a total of 61 writing excerpts were collected: 34 from 24 TAs at the start of the semester (pre) and 27 from 21 TAs at the end of the semester (post). Representative example excerpts are presented in Table IV. However, it is the TAs - and not the excerpts - that we wish to compare. If we counted only the excerpts, one TA whose writing was the basis of three excerpts would be overrepresented, and perhaps introduce bias in the results. Thus, the 61 excerpts were associated with the TAs who wrote them, and these data are indicated in columns 2 and 3 of Table VI. Since the writing was submitted anonymously, it is not possible to look at the change in views for individual TAs. Three TAs are excluded from this table ( 2 pre and 1 post) because their writing resulted in two or more excerpts that contained both transmissionist and constructivist views of teaching. The Fisher-Irwin test [65] allows us to reject

TABLE VI. Categorization of TA writing excerpts into two views of teaching. Columns 2 and 3 indicate categorization by TA for 22 (pre) and 20 (post) TAs.

\begin{tabular}{lrr}
\hline \hline & Pre & Post \\
\hline Transmissionist & 16 & 9 \\
Constructivist & 6 & 11 \\
\hline \hline
\end{tabular}


the hypothesis of independence between TA view of teaching and the pre and post condition $(p<0.05)$, indicating a positive and statistically significant effect when comparing the 22 (pre) and 20 (post) TAs whose writing provided unambiguous transmissionist or constructivist views of teaching.

\section{E. Did TA behaviors change to be more supportive of inquiry learning?}

RIOT observations for three semesters are shown in Fig. 4. The fraction of lab time is shown, with colors indicating the different TA-student interaction types. Each week (i.e., each column) is the mean of these fractions over 7 or 8 TAs, depending on how many were observed that week. Each semester a new batch of TAs was observed, so these changes indicate how TAs' interactions with students change during their first semester working as a lab TA. For clarity, no error bars are displayed. Typical values of the standard error in the mean are $2 \%-3 \%$.

During the first semester of observations, the lab was run using a highly structured lab curriculum [51] and no specialized lab TA professional development was provided. The shift from watching and scanning toward closed dialogue (i.e., from observing to talking) aligns with our observations that the TAs became more confident in talking with students over the course of the semester. However, the TAs spent very little time engaging in (open-ended) dialogue that allowed students to actively develop understanding or expertise.

In the second semester, the highly structured curriculum was retained while specialized lab TA professional development was introduced via weekly, one-hour lab TA meetings. While the distribution of TA-student interactions is comparable to those in the first semester during week 3 , by week 6 the difference between the two semesters has become clear and distinct. Unlike in the first and third semesters, in the second semester the behaviors of this new batch of TAs continued to evolve during the semester, perhaps reflecting slow progress as the TAs negotiated tension between the traditional, highly structured lab learning activities and the encouragement from the lab TA professional development program that TAs support student learning using techniques designed for inquiry learning.

In this second semesters, the TAs spent substantially more time actively listening to their students and engaging in open-ended discussion (i.e., as in the first semester, TAs went from observing to talking, but now with more open dialogue). In our observations, we noted that the TAs seemed more comfortable in their roles as educators than they had in past semesters. In general, the TAs were more willing to simply listen to their students, rather than always feeling the need to provide answers. This semester in particular showcased the utility of the lab TA professional development program, as the training helped TAs engage in epistemologically beneficial instructional practices even though the traditional, highly structured lab curriculum used during this semester was built around learning activities that were not designed to develop students' epistemology.

The third semester saw a switch to a RealTime Physicsbased active learning curriculum [58]. This switch included adopting checkpoints, as described above, and continuing to provide professional development activities in the lab TA meetings. The difference between the second semester and the third semester can be attributed to the change in pedagogy. In this semester, nearly a third of TA-student interaction time was devoted to open-ended dialogue, including as early as week 3 , and a similar fraction to closed dialogue. We observed that the TAs this semester generally

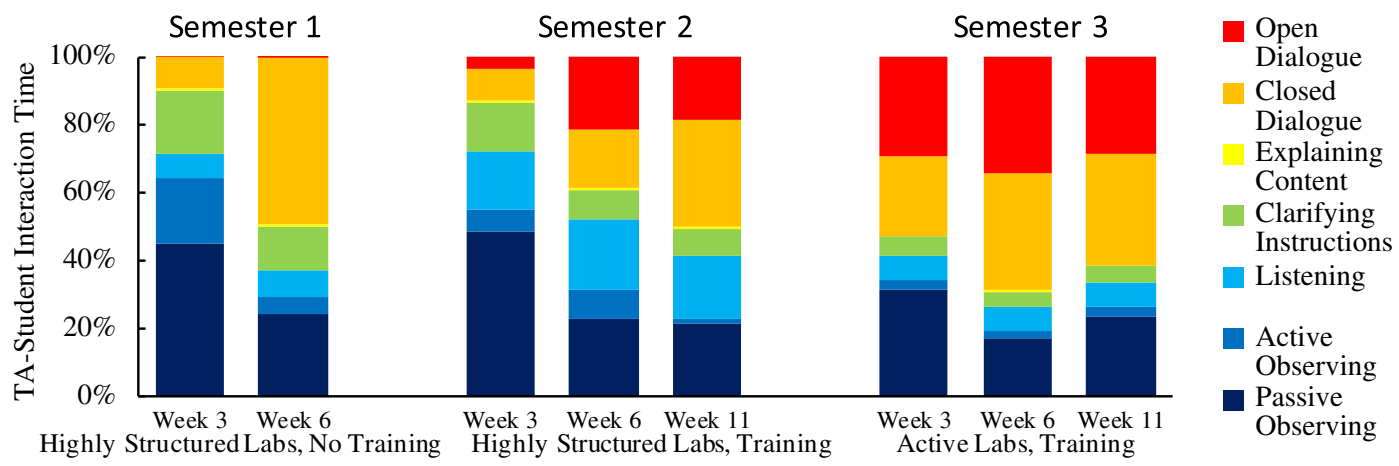

FIG. 4. Comparison of TA-student interactions across three semesters, averaged over all observed TAs. A different set of TAs was observed each semester, and all TAs observed were working their first semester as a lab TA. In the first semester, a highly structured lab curriculum was used with no lab TA professional development. TAs become more comfortable engaging in dialogue with students, but do not practice open dialogue, which would support inquiry-style learning. In the second semester, lab TAs received specialized professional development and demonstrated increasing levels of both open dialogue and listening to students over the semester. In the third semester, an active-engagement curriculum was adopted and the lab TA professional development continued. In this third semester, TAs engaged in open dialogue throughout the semester. 
demonstrated both confidence and purposefulness when interacting with students, and were especially likely to employ the strategies for supporting inquiry learning that were introduced as part of the lab TA professional development. In other words, the benefits of the professional development program on TA practices become evident earlier in the semester in the third semester in which inquiry learning was used compared to second semester when the lab was traditional.

\section{DISCUSSION AND SUMMARY}

The findings described above suggest that, on average, our professional development program helped improve lab TAs' views about teaching and learning and their concomitant teaching behaviors in the lab. Our instantiation of the lab TA professional development program, designed using the framework of the cognitive apprenticeship and expectancy-value theories, did an adequate job of moving many graduate student TAs toward a higher level of teaching effectiveness. However, as illustrated by the interviews with two representative TAs and one TA with a uniquely low level of interest and self-efficacy, the average results presented here mask inadequacy of certain aspects of the implementation of effective pedagogical practices. For example, Alan struggled to avoid touching the students' apparatus and Ted largely did not buy in.

As viewed alongside the measuring stick of the fourphase framework of interest development, many TAs (including Alan and Emily) experienced substantial growth in their interest. One TA (Ted), on the other hand, did not engage deeply during the activities which were part of the lab TA professional development program, nor did he employ the teaching strategies in his lab. It appears from the interviews that this TA, about a year away from defending his Ph.D. thesis and the only member of his cohort in the pool of lab TAs in that semester, may have viewed the lab teaching role as an unwanted burden. In order to account for Ted's lack of involvement, we refer back to expectancy-value theory. Unlike most of his fellow TAs, Ted came with a very low level of interest and did not find enjoyment in his work as a lab TA throughout the semester. Thus, our focus during the professional development program on developing interest with inspiration from the four-phase interest development theory was not appropriate for a TA with a very low level of initial interest as an educator. Instead, in order to adopt the pedagogical techniques and approaches advocated in our professional development program, Ted may have required that the program be built around a utility value model [74] focusing, e.g., on more explicit discussions of how developing teaching skills could help his career goals, or on how improved teaching practices might improve his course evaluations.

Both the excerpt categorization and the RIOT observations indicated that, while improved in their capacity to support inquiry learning, the instructional views and practices of the TAs continued to be an admixture of transmissionist and constructivist views. For example, in the "post" condition, nine TAs continued to describe student learning using a transmissionist view, and around $40 \%$ of TA-student interactions in week 11 with the active labs and TA training continued to consist of closed dialogue. We interpret these results as indicative of two things. First, the process of developing expertise as an educator should be viewed as a long and sometimes difficult process: those nine TAs who continue to ascribe to a transmissionist view of teaching at least in some cases may have shifted in their thinking but still have some distance to go before they fully adopt a constructivist view. These TAs may benefit from more practice teaching, and perhaps another semester as a lab TA with our professional development program. Second, we note that masterful educators typically use a mix of methods. In our labs, TAs are given enough freedom and responsibility that it would be remiss to only engage in open dialogue with students, or to never clarify the instructions for them. Thus, the argument we seek to make is that the overall balance of TA-student interactions was better attuned to supportive inquiry learning with the professional development than without it.

Equity was an important consideration in the design and implementation of our lab TA professional development program. Several of the lab TA meetings included activities that sought to help TAs learn to recognize and combat inequitable student work, such as gendered task division and conversational dominance. As was the case for Alan in the interview above, it was common for TAs to engage with these activities, and to think about how they could respond to inequities. In practice, our informal observations suggested that most TAs adopted techniques for responding to conversational dominance (such as posing questions directly to the quieter partner) and were diligent about rotating group composition at least once during the semester in order to reduce the impact of gendered task division. The higher level of engagement with these activities suggests that most TAs bought into the topic of equity although more work needs to be done.

In summary, our model of lab TA professional development based on weekly lab TA meetings took into account both cognitive and motivational aspects to engage TAs effectively. This type of lab TA professional development can be successful at preparing graduate student TAs to effectively support student learning in the labs. Moreover, our findings suggest that over the span of one semester, TAs who engage in lab TA professional development can develop effective attitudes and approaches to supporting student learning. These results hold regardless of the nature of the curriculum used in the lab course. Our lab TAs demonstrated the use of effective forms of student-instructor 
interactions regardless of whether the students were in a lab course that used a traditional, highly structured curriculum or a transformed, inquiry-based approach.

Equally importantly, the success of lab TA professional development at achieving these goals is contingent at least partly on the buy-in and engagement from the graduate students who undertake it. Including expectancy-value theory and the four-phase interest development theory as the motivational framework inspiring our work was important for success of the program and ensuring buy-in and engagement from TAs. We also note that the close relationship between the lab TA meetings and TAs' instructional work in the labs may have allowed a synergy that is not available in all cases of TA professional development.

Several avenues for future work are suggested by the interviews. For example, as Emily pointed out, discussions about the nature of science are difficult for TAs to initiate. Based on these types of factors, our lab curriculum has been revised to incorporate explicit discussion of this important topic in the questions that students answer during the lab, rather than asking TAs to initiate conversations about the nature of science. Another place for improvement was highlighted in the interviews with TAs such as Alan and Ted, who described a need to continue developing and refining strategies to ensure equity and inclusion of all students in these types of physics labs. The task division and dominance activities have been useful first steps, but we are also committed to refining the lab curriculum and environment to eliminate unequal opportunities for student learning in these types of labs.

\section{ACKNOWLEDGMENTS}

We wish to thank Sonja Cwik, Yangqiuting Li, Ly Malespina, Bob Devaty, Angie, Mark, our panel of science educators at dB-SERC, faculty who helped identify goals for the lab, the TAs who served as our research partners, and the anonymous reviewers for their time and valuable insight. We also thank the NSF for Grant No. DUE-1524575.
[1] J. A. Gilreath and T. F. Slater, Training graduate teaching assistants to be better undergraduate physics educators, Phys. Educ. 29, 200 (1994).

[2] E. Marshman, R. Sayer, C. Henderson, and C. Singh, Contrasting grading approaches in introductory physics and quantum mechanics: The case of graduate teaching assistants, Phys. Rev. Phys. Educ. Res. 13, 010120 (2017).

[3] E. Marshman, R. Sayer, C. Henderson, E. Yerushalmi, and C. Singh, The challenges of changing teaching assistants' grading practices: Requiring students to show evidence of understanding, Can. J. Phys. 96, 420 (2018).

[4] E. M. Marshman, A. Maries, R. T. Sayer, C. Henderson, C. Singh, and E. Yerushalmi, Physics postgraduate teaching assistants' grading approaches: Conflicting goals and practices, Eur. J. Phys., https://doi.org/10.1088/13616404/ab9890 (2020).

[5] C. Singh, Categorization of problems to assess and improve proficiency as teachers and learners, Am. J. Phys. 77, 73 (2009).

[6] S.-Y. Lin, C. Henderson, W. Mamudi, C. Singh, and E. Yerushalmi, Teaching assistants' beliefs regarding example solutions in introductory physics, Phys. Rev. ST Phys. Educ. Res. 9, 010120 (2013).

[7] M. Good, E. Marshman, E. Yerushalmi, and C. Singh, Physics teaching assistants' views of different types of introductory problems: Challenge of perceiving the instructional benefits of context-rich and multiple-choice problems, Phys. Rev. Phys. Educ. Res. 14, 020120 (2018).

[8] A. Maries and C. Singh, Exploring one aspect of pedagogical content knowledge of teaching assistants using the test of understanding graphs in kinematics, Phys. Rev. ST Phys. Educ. Res. 9, 020120 (2013).
[9] A. Maries and C. Singh, Teaching assistants' performance at identifying common introductory student difficulties in mechanics revealed by the Force Concept Inventory, Phys. Rev. Phys. Educ. Res. 12, 010131 (2016).

[10] N. I. Karim, A. Maries, and C. Singh, Exploring one aspect of pedagogical content knowledge of teaching assistants using the Conceptual Survey of Electricity and Magnetism, Phys. Rev. Phys. Educ. Res. 14, 010117 (2018).

[11] J. Spears and D. Zollman, Orientation for the new teaching assistant-A laboratory based program, Am. J. Phys. 42, 1062 (1974).

[12] L. D. Muhlestein and B. DeFacio, Teaching graduate teaching assistants to teach, Am. J. Phys. 42, 384 (1974).

[13] A. Armenti and G. F. Wheeler, Hawthorne effect and quality teaching: Training graduate teaching assistants to teach, Am. J. Phys. 46, 121 (1978).

[14] F. S. Mozer and S. M. Napell, Instant replay and the graduate teaching assistant, Am. J. Phys. 43, 242 (1975).

[15] F. Lawrenz, P. Heller, R. Keith, and K. Heller, Training the teaching assistant, J. Coll. Sci. Teach. 22, 106 (1992).

[16] A. Maries, Preparing the next generation of educators, in Active Learning in College Science, edited by J. J. Mintzes and E. Walter (Springer, New York, 2020).

[17] Recruiting and Educating Future Physics Teachers: Case Studies and Effective Practices, edited by C. Sandifer and E. Brewe (Physics Teacher Education Coalition, College Park, MD, 2015).

[18] E. L. Jossem, Resource letter EPGA-1: The education of physics graduate assistants, Am. J. Phys. 68, 502 (2000).

[19] R. M. Goertzen, R. E. Scherr, and A. Elby, Tutorial teaching assistants in the classroom: Similar teaching behaviors 
are supported by varied beliefs about teaching and learning, Phys. Rev. ST Phys. Educ. Res. 6, 010105 (2010).

[20] R. M. Goertzen, R. E. Scherr, and A. Elby, Respecting tutorial instructors' beliefs and experiences: A case study of a physics teaching assistant, Phys. Rev. ST Phys. Educ. Res. 6, 020125 (2010).

[21] A. L. Gretton, T. Bridges, and J. M. Fraser, Transforming physics educator identities: TAs help TAs become teaching professionals, Am. J. Phys. 85, 381 (2017).

[22] N. G. Holmes, M. S. Martinuk, J. Ives, and M. Warren, Teaching assistant professional development by and for TAs, Phys. Teach. 51, 218 (2013).

[23] J. B. Velasco, A. Knedeisen, D. Xue, T. L. Vickrey, M. Abebe, and M. Stains, Characterizing instructional practices in the laboratory: The laboratory observation protocol for undergraduate STEM, J. Chem. Educ. 93, 1191 (2016).

[24] M. Wilcox, C. C. Kasprzyk, and J. Chini, Observing teaching assistant differences in tutorials and inquiry-based labs, in Proceedings of the Physics Education Research Conference, College Park, MD, 2015 (American Association of Physics Teachers, College Park, MD, 2015), pp. 371-374, https://doi.org/10.1119/perc.2015.pr.088.

[25] G. DeBeck, S. Settelmeyer, S. Li, and D. Demaree, TA beliefs in a SCALE-UP style classroom, AIP Conf. Proc. 1289, 121 (2010).

[26] K. M. Koenig, R. J. Endorf, and G. A. Braun, Effectiveness of different tutorial recitation teaching methods and its implications for TA training, Phys. Rev. ST Phys. Educ. Res. 3, 010104 (2007).

[27] R. M. Goertzen, R. E. Scherr, and A. Elby, Accounting for tutorial teaching assistants' buy-in to reform instruction, Phys. Rev. ST Phys. Educ. Res. 5, 020109 (2009).

[28] E. M. Duffy and M. M. Cooper, Assessing TA buy-in to expectations and alignment of actual teaching practices in a transformed general chemistry laboratory course, Chem. Educ. Res. Pract. 21, 189 (2020).

[29] M. Wilcox, Y. Yang, and J. J. Chini, Quicker method for assessing influences on teaching assistant buy-in and practices in reformed courses, Phys. Rev. Phys. Educ. Res. 12, 020123 (2016).

[30] J. J. Chini and A. Al-Rawi, Alignment of TAs' beliefs with practice and student perception, AIP Conf. Proc. 1513, 98 (2013).

[31] J. A. Luft, J. P. Kurdziel, G. H. Roehrig, and J. Turner, Growing a garden without water: Graduate teaching assistants in introductory science laboratories at a doctoral/ research university, J. Res. Sci. Teach. 41, 211 (2004).

[32] A. Collins, J. S. Brown, and A. Holum, Cognitive apprenticeship: Making thinking visible, Am. Educ. 15, 6 (1991).

[33] J. S. Eccles and A. Wigfield, Motivational beliefs, values, and goals, Annu. Rev. Psychol. 53, 109 (2002).

[34] J. E. Parsons, T. Adler, R. Futterman, S. Goff, C. Kaczala, J. Meece, and C. Midgley, Expectancies, values, and academic behaviors, in Achievement and Achievement Motives, edited by J. Spence (Freeman, San Francisco, 1983), pp. 75-146.

[35] A. Bandura, Self-efficacy mechanism in human agency., Am. Psychol. 37, 122 (1982).

[36] S. Hidi and K. A. Renninger, The four-phase model of interest development, Educ. Psychol. 41, 111 (2006).
[37] N. Lasry, E. Charles, and C. Whittaker, When teachercentered instructors are assigned to student-centered classrooms, Phys. Rev. ST Phys. Educ. Res. 10, 010116 (2014).

[38] B. V. Dusen, L. Langdon, and V. Otero, Learning assistant supported student outcomes (LASSO) study initial findings, in Proceedings of the Physics Education Research Conference, College Park, MA, 2015 (Ref. [24]), pp. 343346, https://doi.org/10.1119/perc.2015.pr.081.

[39] X. Herrera, J. Nissen, and B. V. Dusen, Student outcomes across collaborative-learning environments, in Proceedings of the Physics Education Research Conference, Washington, DC, 2018 (American Association of Physics Teachers, College Park, MD, 2018), https://doi.org/10.1119/ perc.2018.pr.Herrera.

[40] M. Good, E. Marshman, E. Yerushalmi, and C. Singh, Graduate teaching assistants' views of broken-into-parts physics problems: Preference for guidance overshadows development of self-reliance in problem solving, Phys. Rev. Phys. Educ. Res. 16, 010128 (2020).

[41] D. Doucette, Lab TA TRAINING, http://labtatraining.com.

[42] D. Doucette, R. Clark, and C. Singh, Hermione and the secretary: How gendered task division in introductory physics labs can disrupt equitable learning, Eur. J. Phys. 41, 035702 (2020).

[43] K. N. Quinn, K. L. McGill, M. M. Kelley, E. M. Smith, and N. Holmes, Who does what now? How physics lab instruction impacts student behaviors, in Proceedings of the Physics Education Research Conference, Washington, DC 2018 (Ref. [39]), https://doi.org/10.1119/perc.2018 .pr.Quinn.

[44] K. N. Quinn, M. M. Kelley, K. L. McGill, E. M. Smith, Z. Whipps, and N. G. Holmes, Group roles in unstructured labs show inequitable gender divide, Phys. Rev. Phys. Educ. Res. 16, 010129 (2020).

[45] P. Heller and M. Hollabaugh, Teaching problem solving through cooperative grouping. Part 2: Designing problems and structuring groups, Am. J. Phys. 60, 637 (1992).

[46] C. Turpen, A. Gupta, J. Radoff, A. Elby, H. Sabo, and G. Quan, Successes and challenges in supporting undergraduate peer educators to notice and respond to equity considerations within design teams, in Proceedings of the 2018 ASEE Annual Conference and Exposition, Salt Lake City, UT (American Society for Engineering Education, Washington, DC, 2018).

[47] H. Sabo, J. Radoff, A. Elby, A. Gupta, and C. Turpen, Role-playing as a tool for helping LAs sense-make about inequitable team dynamics, in Proceedings of the Physics Education Research Conference, Washington, DC, 2018 (Ref. [39]), https://doi.org/10.1119/perc.2018.pr.Sabo.

[48] National Science Teachers Association, NSTA position statement: The nature of science, https://www.nsta.org/ about/positions/natureofscience.aspx.

[49] F. J. Rutherford and A. Ahlgren, Science for All Americans (Oxford University Press, Oxford, New York, 1990), Chap. 1.

[50] D. Doucette, R. Clark, and C. Singh, All aboard! Challenges and successes in professional development for physics lab TAs, in Proceedings of the Physics Education Research Conference, Provo, UT, 2019 
(American Association of Physics Teachers, College Park, MD, 2019), https://doi.org/10.1119/perc.2019.pr.Doucette.

[51] R. Clark, Introduction to Laboratory Physics, 3rd ed. (Kendall Hunt, Dubuque, IA, 2012).

[52] N. G. Holmes and E. M. Smith, Operationalizing the AAPT learning goals for the lab, Phys. Teach. 57, 296 (2019).

[53] B. M. Zwickl, N. Finkelstein, and H. J. Lewandowski, The process of transforming an advanced lab course: Goals, curriculum, and assessments, Am. J. Phys. 81, 63 (2013).

[54] AAPT Committee on Laboratories, AAPT Recommendations for the Undergraduate Physics Laboratory Curriculum (AAPT, College Park, MD, 2015).

[55] L. Bao and K. Koenig, Physics education research for 21 st century learning, Discip. Interdiscip. Sci. Educ. Res. 1, 2 (2019).

[56] A. A. Bless, Cook-book laboratory work, Am. Phys. Teach. 1, 88 (1933).

[57] D. A. Dale, J. Sutter, and D. Kloster, Asking real-world questions with inquiry-based labs, Phys. Teach. 57, 547 (2019).

[58] D. R. Sokoloff, P. W. Laws, and R. K. Thornton, RealTime Physics: Active learning labs transforming the introductory laboratory, Eur. J. Phys. 28, S83 (2007).

[59] M. Johnson, Facilitating high quality student practice in introductory physics, Am. J. Phys. 69, S2 (2001).

[60] R. K. Thornton and D. R. Sokoloff, Learning motion concepts using real-time microcomputer-based laboratory tools, Am. J. Phys. 58, 858 (1990).

[61] V. K. Otero and D. B. Harlow, Getting started in qualitative physics education research, Rev. PER 2, 1 (2009).

[62] D. Doucette, R. Clark, and C. Singh, What's happening in traditional and inquiry-based introductory labs? An integrative analysis at a large research university, in Proceedings of the Physics Education Research
Conference, Washington, DC, 2018, https://doi.org/ 10.1119/perc.2018.pr.Doucette.

[63] A. King, From sage on the stage to guide on the side, Coll. Teach. 41, 30 (1993).

[64] J. Cohen, A coefficient of agreement for nominal scales, Educ. Psychol. Meas. 20, 37 (1960).

[65] J. L. Fleiss, B. Levin, and M. C. Paik, Statistical Methods for Rates and Proportions (John Wiley \& Sons, New York, 2013).

[66] J. R. Landis and G. G. Koch, The measurement of observer agreement for categorical data, Biometrics 33, 159 (1977).

[67] J. Piaget, The Origins of Intelligence in Children (International Universities Press, Inc., New York, 1952).

[68] E. A. West, C. A. Paul, D. Webb, and W. H. Potter, Variation of instructor-student interactions in an introductory interactive physics course, Phys. Rev. ST Phys. Educ. Res. 9, 010109 (2013).

[69] C. Paul and E. West, Using the Real-time Instructor Observing Tool (RIOT) for reflection on teaching practice, Phys. Teach. 56, 139 (2018).

[70] C. Paul and A. Reid, SJSU Real-time instructor observing tool, https://www.sjsu.edu/people/cassandra.paul/RIOT/.

[71] C. Power, A critical review of science classroom interaction studies, Stud. Sci. Educ. 4, 1 (1977).

[72] J. Wei, D. F. Treagust, M. Mocerino, A. D. Lucey, M. G. Zadnik, and E. D. Lindsay, Understanding interactions in face-to-face and remote undergraduate science laboratories: A literature review, Discip. Interdiscip. Sci. Educ. Res. 1, 14 (2019).

[73] E. Hickok, Teaching practices of graduate teaching assistants, Master's Thesis, San Jose State University, 2016.

[74] C. S. Hulleman, O. Godes, B. L. Hendricks, and J. M. Harackiewicz, Enhancing interest and performance with a utility value intervention, J. Educ. Psychol. 102, 880 (2010). 